Aim of the study: The purpose of the study was to evaluate patients with borderline ovarian tumors.

Material and methods: Clinical features, treatment and survival status of 100 patients with borderline ovarian tumors were retrospectively evaluated between 1998 and 2007.

Results: Patients' mean age was 37.75 years (range: 15-72); 22 of them were postmenopausal. Histopathological diagnoses were serous, mucinous, endometrioid and clear cell in 54\%, 41\%, $2 \%$ and $3 \%$ of the patients, respectively; 70 patients had stage IA disease, 8 were at stage IB, 16 at stage IC, 2 at stage IIIA, 3 at stage IIIB and 1 at stage IIIC. Restaging laparotomies were performed on 19 patients; fertility-sparing surgery was performed on 52 patients; 2 patients received chemotherapy because of advanced-stage disease. All patients are currently alive. The 5-year diseasefree survival rate for 71 cases was $100 \%$. Conclusions: Borderline ovarian tumors have excellent prognoses, and fertilityconserving surgery can be performed in young patients with early-stage disease.

Key words: borderline ovarian tumors, survival, fertility-sparing surgery.

\section{Borderline ovarian tumors: a study of 100 cases from a Tertiary Care Hospital}

\author{
Ahmet Uysal ${ }^{12}$, Semih Mun ${ }^{1}$, Fatma Uysal ${ }^{3}$, Murat Öztekin'1, \\ Cem Büyüktosun ${ }^{1}$, Salim Șehirali' ${ }^{1}$, Ömer Bașoğul', Cüneyt E. Taner ${ }^{1}$
}

${ }^{1}$ Ministry of Health, Aegean Maternity and Teaching Hospital, Department of Obstetrics and Gynecology, Izmir, Turkey

${ }^{2}$ Çanakkale Onsekiz Mart University Faculty of Medicine, Department of Obstetrics and Gynecology, Çanakkale, Turkey

3 Ministry of Health, Aegean Maternity and Teaching Hospital, Department of Radiology, Izmir, Turkey

\section{Introduction}

Epithelial ovarian tumors of low malignant potential constitute a subgroup of ovarian malignancies called borderline ovarian tumors. Borderline tumors occur in younger women, present at an earlier stage and have a favorable prognosis. The incidence rate of borderline ovarian tumors is lower than that of invasive cancers with borderline ovarian tumors ranging from 12 to $33 \%$ among epithelial tumor series [1-3]. Mean age at diagnosis is 47, with the highest frequency in women 30-50 years of age [3]. The most common histological type is serous; the others are mucinous, endometrioid and, rarely, clear cell. When tumors are localized to one or both ovaries, prognosis is excellent [4, 5]. However, the most appropriate management of patients with extra-ovarian disease is unclear, as some tumors progress despite aggressive cytoreductive surgery and chemotherapy [6].

The purpose of this retrospective study was to evaluate the clinical features, treatment and survival status of patients with borderline ovarian tumors.

\section{Material and methods}

One hundred eight patients with borderline ovarian tumors who were treated at the Aegean Maternity and Teaching Hospital between January 1998 and December 2007 were retrospectively reviewed. Follow-up information was not available for eight patients, who were therefore excluded. Clinical features, treatment and survival data were all noted. All patients were treated surgically; their tumors were classified by our hospital's pathologists in accordance with WHO criteria for histological typing [7]. During the study period, we utilized intraoperative assessments (frozen sections) in 60/100 cases. Followup was performed by reviewing patients' hospital records, or by contracting patients and reviewing them personally.

Staging followed the FIGO system, which, for borderline ovarian tumors, is similar to that used for ovarian epithelial carcinomas (Fig. 1). Suggested FIGO guidelines include taking specimens from the omentum; intestinal serosa and mesentery; pelvic peritoneum including the cul-de-sac, bladder peritoneum, and pelvic wall; and abdominal peritoneum including paracolic gutters, diaphragmatic surface, and retroperitoneal nodes [8].

Statistical analysis was performed using a commercial computer system (SPSS 10.0 for Windows, SPSS Inc., Chicago. IL.).

\section{Results}

Mean age of all patients in the sample was 37.75 years (range: $15-72$ years); 18 patients were younger than 30 years, and 22 patients were postmenopausal. Mean ages were 35.13 years for patients with serous tumors and 


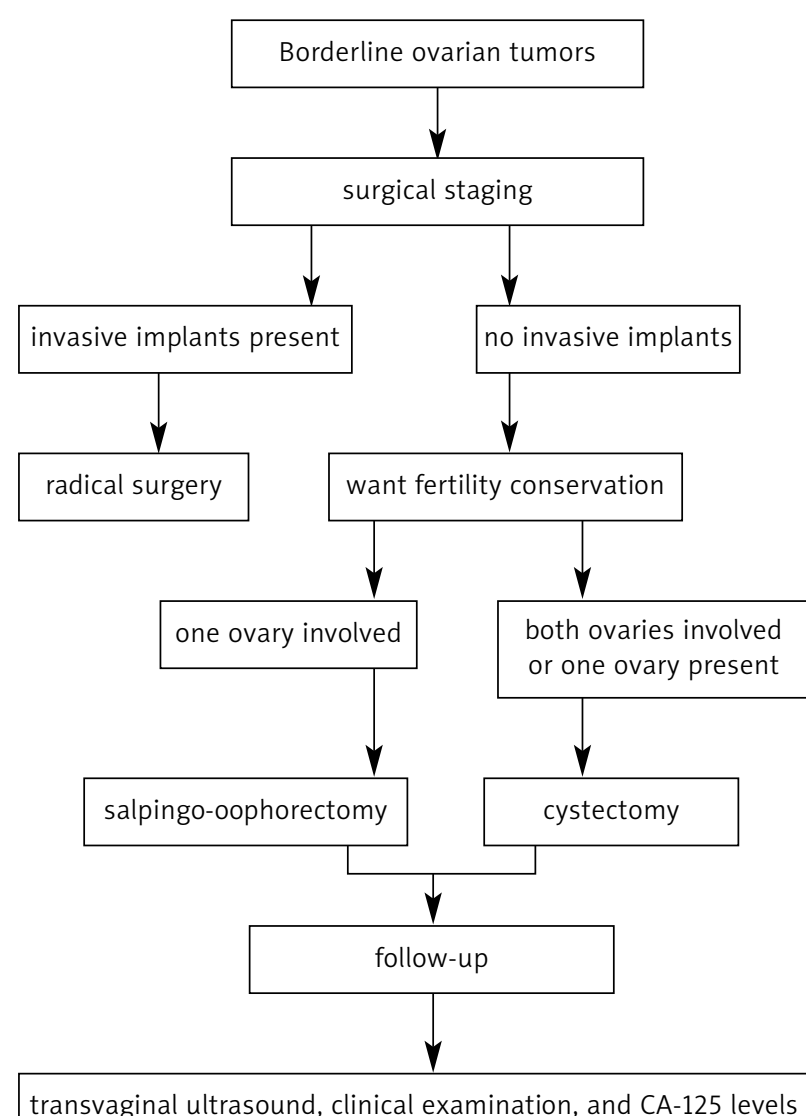

Schematic representation of management and surveillance algorithm for borderline ovarian neoplasms Information from [8] was incorporated in this algorithm.

Fig. 1. Summary of International Federation of Obstetric Gynecology (FIGO) Staging

42.25 years for those with mucinous tumors. Mean parity was 1.6 (range: 0-5). Preoperative ultrasound found mean ovarian mass diameter to be $10.8 \mathrm{~cm}$ (range: $5-21 \mathrm{~cm}$ ), with 9.05 $\mathrm{cm}$ for serous tumors and $15.61 \mathrm{~cm}$ for mucinous tumors. Twenty-two cases were bilateral (22\%; 22/100), of which 17 (77\%; 17/22) were serous and 5 (23\%; 5/22) were mucinous. High CA 125 level (> $35 \mathrm{lU} / \mathrm{ml}$ ) was detected in 46 cases, including 31 of the 54 serous tumors (57\%), 11 of the 41 mucinous tumors (27\%), 2 of the 3 clear cell tumors (67\%), and 2 of the 2 endometrioid tumors (100\%). Histological diagnosis and stage distribution are shown in Table 1.
Nineteen patients underwent restaging laparotomies after diagnosis. Three patients had pseudomyxoma peritonei. As we could not show gastrointestinal origin in these cases using upper or lower gastrointestinal endoscopies, we accepted them as having primary ovarian origin. Patients' operations are shown in Table 2.

Fertility-sparing surgery (conservation of the uterus and at least one ovary, in patients younger than 40 years) was performed for 52 patients. Patients with advanced disease underwent hysterectomy, bilateral salpingo-oophorectomy, pelvic and para-aortic lymphadenectomy sampling, omentectomy and cytoreductive surgery. No residual tumor was larger than $1 \mathrm{~cm}$ after surgery. The 22 patients with advanced disease received cisplatin-based chemotherapy. The mean number of extracted lymph nodes was 14.5 in 22 cases who underwent pelvic and para-aortic lymphadenectomy sampling. One patient had lymph metastasis in 3 of her 16 extracted lymph nodes.

Mean follow-up was $62 \pm 2$ months (range: 4-120 months). All patients in this study are currently alive; the 5-year tumorfree survival rate is 100\% for 71 patients; 9 had recurrence (9\%); 20 are still within 5 years of their diagnoses. Four patients who had stage IA disease had pregnancies; they delivered with no relevant problems.

Patients' characteristics (an also patients who had serous and mucinous tumor comparing table, diagnostic measurements as well as surgery summary) are shown in Table 3.

\section{Discussion}

Borderline ovarian tumors occur in women of all ages, with an average age in the mid-40s. They account for $9.2-16.3 \%$ of ovarian malignancies. Serous and mucinous types make up the vast majority; other histological types are endometrioid and clear cell [1-3].

Recent cytogenetic advances have given unique insights into the pathogenesis and behavior of serous borderline ovarian tumors. In several studies, investigators found that only a small subset of serous cyst adenomas progress to serous borderline ovarian tumors, and that activating mutations of $B R A F$ and KRAS genes are early events in tumorigenesis of borderline ovarian tumors [9]. Anfinan et al. reported the mean age of 138 patients with borderline ovarian tumors as 46 years; Sanci et al. reported it to be 47.1 years in 96 cases [1-3]. In our study, mean age was 37.8 years -35.1 years for those with serous tumors, and 42.2 years for patients

Table 1. Histological subtypes of borderline ovarian tumors and stages of the cases according to the FIGO system

\begin{tabular}{lccccccc} 
Histopathological subtypes of BOTs & \multicolumn{7}{c}{ Stage $(n$ and \%) } \\
\cline { 2 - 7 } & IA & IB & IC & IIIA & IIIB & IIIC & Total $(n$ and \%) \\
\hline serous BOT & 36 & 6 & 10 & - & 1 & 1 & 54 \\
\hline mucinous BOT & 32 & 1 & 5 & 2 & 1 & - & 41 \\
\hline endometrioid BOT & 2 & - & - & - & - & - & 2 \\
clear-cell BOT & - & 1 & 1 & - & 1 & - & 3 \\
\hline total $(n$ and \%) & 70 & 8 & 16 & 2 & 3 & 1 & 100
\end{tabular}

BOT - borderline ovarian tumor 
with mucinous tumors. Patients with borderline tumors tend to be younger than those who develop invasive carcinomas $[8,11]$.

Kliman et al. reported $51.3 \%$ of 76 tumors to be mucinous and $38.2 \%$ serous [10]. In another study, $60 \%$ of tumors were mucinous and $37 \%$ were serous [11]. In our study, 54\% of tumors were serous and $41 \%$ were mucinous. Other studies also reported more serous tumors than mucinous tumors in their series [10-12].

Buttin et al. identified micro-invasion by the primary ovarian tumor as a risk factor for recurrence and death [13]. Seidmen et al. suggested that borderline tumors be classified as benign and malignant [14]. Survival for patients whose serous borderline tumors were confined to the ovaries was $100 \%$, whereas those with invasive peritoneal implants and with micropapillary serous carcinomas had a 30-40\% mortality rate; these tumors were thus classified as carcinomas.

The rate of stage I disease among borderline ovarian tumor diagnoses is reportedly $67.5-91.6 \%[3-9,15]$; it was $94 \%$ in our group.

Some authors advise treating with fertility-sparing surgery and adequate surgical staging procedures, especially in young stage I patients, as no such patients have died of tumors [4-6, 11]. Marice et al. reported that conservative management of ovarian tumors with low potential for malignancy significantly increases risk of recurrence, but does not affect overall survival [16]. Morris et al. also noted that recurrence was more frequent in patients treated with ovarian cystectomy than in those treated with oophorectomy [15].

Identifying clinical disease stage is crucial in determining prognosis. The overall 5 -year survival rate for patients with stage I disease is reported to be approximately 95\% [9-11, 16], but survival rates decrease to $40-75 \%$ in stage II and $56-$ $65 \%$ in stage III $[1-3,16]$. Upstaged disease has been reported at restaging surgery for borderline ovarian tumors after initial conservative surgery [4-6].

Tamokoshi et al. reported that the patients with borderline serous/mucinous tumors at stages II and III had 5- and 9-year survival rates of $91.7 \%$ and $73.3 \%$, and $38.9 \%$ and $13.0 \%$, respectively [9]. They found patients with advanced mucinous tumors to have poor prognoses-emphasizing the need to develop more effective treatments for mucinous tumors. Similar survival rates were reported by other authors [1-3].

Postoperative treatment of borderline ovarian tumors is controversial. Patients treated with adjuvant therapy reportedly show no difference in survival rate compared with those treated with surgery alone [5-16]. We administered chemotherapy to 22 patients with advanced disease. In one study, most patients received adjuvant chemotherapy and none had recurrent tumor in stage I patients [9]. Others reported recurrence rates of $2-7 \%$ in patients with stage I borderline ovarian tumors [1-3]. In our study the recurrence rate for all stages was $9 \%$. Tamokoshi et al. reported that they had a clinically complete response in 5 of 16 patients with residual tumors of $<2 \mathrm{~cm}$ [9]. Their reported overall response rate was $50 \%$ in cases with residual tumors of $<2 \mathrm{~cm}$, but they found no effect with cisplatin-based chemotherapy in patients with gross residual tumors, especially with mucinous tumors.
Table 2. Operations performed for borderline ovarian tumors

\begin{tabular}{|cc|}
\hline Operation & $n$ \\
\hline TAH + BSO & 48 \\
\hline USO & 26 \\
\hline USO + contralateral cystectomy & 1 \\
\hline unilateral cystectomy & 25 \\
\hline PPLA & 22 \\
\hline appendectomy & 40 \\
\hline
\end{tabular}

$T A H+B S O-$ total abdominal hysterectomy and bilateral salpingooophorectomy; USO - unilateral salpingo-oophorectomy; PPLA - pelvic paraaortic lymphadenectomy

Table 3. Patients' characteristics, treatment, diagnosis and surgery summary

\begin{tabular}{|c|c|c|}
\hline & \multicolumn{2}{|c|}{ Age } \\
\hline & $\begin{array}{l}\text { mean } \\
37.75\end{array}$ & $\begin{array}{l}\text { range } \\
15-72\end{array}$ \\
\hline & \multicolumn{2}{|c|}{ Menopausal status } \\
\hline & $\begin{array}{c}\text { premenopausal } \\
78\end{array}$ & $\begin{array}{c}\text { postmenopausal } \\
22\end{array}$ \\
\hline & \multicolumn{2}{|c|}{ Borderline ovarian tumors } \\
\hline & serous & mucinous \\
\hline Age & 35.13 & 42.25 \\
\hline $\mathrm{USG}^{*}$ & $9.05 \mathrm{~cm}$ & $15.61 \mathrm{~cm}$ \\
\hline Bilaterally & $17 / 54$ & $5 / 41$ \\
\hline High CA-125 levels (>35 IU/ml) & $31 / 54$ & $11 / 41$ \\
\hline \multirow{3}{*}{$\begin{array}{l}\text { Chemotherapy for advanced } \\
\text { disease }\end{array}$} & $10 / 54$ & $8 / 41$ \\
\hline & \multicolumn{2}{|c|}{ Fertility sparing surgery } \\
\hline & $\begin{array}{c}\text { yes } \\
52 / 100\end{array}$ & $\begin{array}{c}\text { no } \\
48 / 100\end{array}$ \\
\hline Residual disease ${ }^{\star *}$ & - & 100 \\
\hline $\begin{array}{l}\text { Lymph node dissection for } \\
\text { advanced disease }\end{array}$ & $22 / 100$ & $78 / 100$ \\
\hline Lymph node positivity & $1 / 22$ & $21 / 22$ \\
\hline Extracted lymph node number & $\begin{array}{c}\text { mean } \\
14.5\end{array}$ & $\begin{array}{l}\text { range } \\
8-19\end{array}$ \\
\hline
\end{tabular}

*USG - ultrasonography (mean diameter given)

**residual disease: (> $1 \mathrm{~cm}$ tumor volume after surgery) with pathological confirmation

Current treatment reports are of residual tumors $<1 \mathrm{~cm}$ [1-17]. In our study we had no case with residual tumor $>1$ $\mathrm{cm}$ (with pathological correlation) and had clinically complete responses after chemotherapy in 6 patients with advanced disease.

In conclusion, Patients with borderline ovarian tumors have excellent prognosis. Fertility-conserving surgery can be performed in young patients with early-stage disease.

The authors declare no conflict of interest.

The authors thank "edanz-springer" for language editing. 


\section{References}

1. Anfinan N, Sait K, Ghatage P, Nation J, Chu P. Ten years experience in the management of borderline ovarian tumors at Tom Baker Cancer Centre. Arch Gynecol Obstet 2011; 284: 731-5.

2. Kanat-Pektas M, Ozat M, Gungor T, Dikici T, Yilmaz B, Mollamahmutoglu L. Fertility outcome after conservative surgery for borderline ovarian tumors: a single center experience. Arch Gynecol Obstet 2011; 284: 1253-8.

3. Sanci M, Gultekin E, Cingillioglu B, Gultekin OE, Ozvural S, Emirdar V, Yildirim Y. Second primary cancers following borderline ovarian tumors. Arch Gynecol Obstet 2011; 283: 1391-6.

4. Lawrenz B, Jauckus J, Kupka MS, Strowitzki T, von Wolff M. Fertility preservation in $>1,000$ patients: patient's characteristics, spectrum, efficacy and risks of applied preservation techniques. Arch Gynecol Obstet 2011; 283: 651-6.

5. Abdel-Hady el-S, Abdel-Hady Hemida R, Gamal A, El-Shamey M. Fertility sparing surgery for ovarian tumors in children and young adults. Arch Gynecol Obstet 2012; 285: 469-71.

6. Casey AC, Bell DA, Lage JM, Fuller AF, Nikrui N, Rice LW. Epithelial ovarian tumors of borderline malignancy. Long term follow up. Gynecol Oncol 1993; 50: 316-322.

7. Serov SF, Scully RE, Solvin LH. International histologic class of tumors. No: 9 Histologic typing of ovarian tumors. Geneva Health Organization 1973; 37-41.

8. Cadron I, Leunen K, Van Gorp T, Amant F, Neven P, Vergote I. Management of borderline ovarian neoplasms. J Clin Oncol 2007; 25: 2928-37.

9. Tamakoshi K, Kikkawa F, Nakashima N, et al. Clinical behavior of borderline ovarian tumors: A study of 150 cases. J Surg Oncol 1997; 64: 147-52.

10. Kliman L, Rome RM, Fortune DW. Low malignant potential tumors of the ovary. A study of 76 cases. Obstet Gynecol 1986; 68: 860-7.

11. Lalwani N, Shanbhogue AK, Vikram R, Nagar A, Jagirdar J, Prasad SR. Current update on borderline ovarian neoplazm. AJR Am J Roentgenol 2010; 194: 330-6.

12. Camatte S, Morice P, Atallah D, Pautier P, Lhommé C, Haie-Meder C, Duvillard P, Castaigne D. Lymph node disorder and prognostic value of nodal involvement in patients treated for a borderline ovarian tumor: An analysis of series of 42 lymphadenectomies. J Am Call Surg 2002; 195: 332-338

13. Buttin BM; Herzug TJ, Powell MA, Roder JS, Mutch DG. Epithelial ovarian tumors of low malignant potential. The role of microinvasion. Obstet Gynecol 2002; 99: 11-7.

14. Seidman JD, Ronnet BM, Kurman RJ. Pathology of borderline (low malignant potential) ovarian tumors. Best Practice and Research Clinical Obstetrics and Gynecology 2002; 16: 4: 499-512.

15. Morris RT, Gershensin DM, Silva EG, Fallen M, Morris M, Wharton JT. Outcome and reproductive function after conservative surgery for borderline ovarian tumors. Obstet Gynecol 2000; 95: 541-7.

16. Marice P, Carnatte S, Hassan JE, Pautier P, Duvillard P, Castaigne D. Clinical outcomes and fertility after conservative treatment of ovarian borderline tumors. Fertil Steril 2001; 75: 92-6

17. Fotopoulou C, Schumacher G, Schefold JC, Denkert C, Lichtenegger W, Sehouli J. Systematic evaluation of the intraoperative tumor pattern in patients with borderline tumor of the ovary. Int J Gynecol Cancer 2009; 19: 1550-5.

\section{Address for correspondence}

Ass. Prof. Dr. Ahmet Uysal

Çanakkale Onsekiz Mart University Faculty of Medicine

Department of Obstetrics and Gynecology

Canakkale, Turkey

tel: + 905332635540

e-mail: drahmetuysal@hotmail.com

Submitted: $\quad 3.10 .2012$

Accepted: $\quad$ 15.02.2013 